\title{
The Role of the Environment and Exposome in Atopic Dermatitis
}

\section{Nicholas Stefanovic ${ }^{1}$ Alan D. Irvine 2,3 Carsten Flohr ${ }^{4, *}$}

\section{Address}

${ }^{1}$ St James' Hospital, Dublin, Ireland

${ }^{2}$ Department of Paediatric Dermatology, Children's Health Ireland at Crumlin, Dublin, Ireland

${ }^{3}$ National Children's Research Centre, Crumlin and Clinical Medicine, Trinity College Dublin, Dublin, Ireland

${ }^{*}, 4$ Unit for Population-Based Dermatology Research, St John's Institute of Dermatology, Guy's \& St Thomas' NHS Foundation Trust and King's College London, London, UK

Email: carsten.flohr@kd.ac.uk

This article is part of the Topical Collection on Urticaria and Atopic Dermatitis

Keywords Atopic dermatitis - Atopic eczema · Eczema - Exposome - Environment · Microbiome

\begin{abstract}
Purpose of review Atopic dermatitis (AD) is a chronic inflammatory skin disorder affecting up to $20 \%$ of children and up to $5 \%$ of adults worldwide, contributing to significant disease-related morbidity in this patient cohort. Its aetiopathogenesis is underpinned by multiple factors, including genetic susceptibility, skin barrier defects, a skewed cutaneous immune response and microbiome perturbation in both the skin and the gut. In this review, we aim to examine the biological effects of key environmental exposures (the sum of which is termed the "exposome") at the population, community and individual levels in order to describe their effect on AD pathogenesis.

Recent findings It is now understood that as well as considering the type of environmental exposure with regard to its effect on $A D$ pathogenesis, the dosage and timing of the exposure are both critical domains that may lead to either exacerbation or amelioration of disease. In this review, we consider the effects of population-wide exposures such as climate change, migration and urbanization; community-specific exposures such as air pollution, water hardness and allergic sensitisation; and individual factors such as diet, microbiome alteration, psychosocial stress and the impact of topical and systemic therapy. Summary This review summarises the interaction of the above environmental factors with the other domains of $A D$ pathogenesis, namely, the inherent genetic defects, the skin
\end{abstract}


barrier, the immune system and the cutaneous and gut microbiota. We specifically emphasise the timing and dosage of exposures and its effect on the cellular and molecular pathways implicated in AD.

\section{Introduction}

Atopic dermatitis (syn. atopic eczema) (AD) is a chronic inflammatory skin disorder affecting up to $20 \%$ of children and $10 \%$ of adults worldwide, with inter-regional variability both between and within countries [1-3]. It is associated with a significant symptom burden, including pruritus, pain and sleep disturbance. A negative impact on self-esteem and educational/work performance are features associated with an adverse impact on an individual's quality of life [4]. Furthering our knowledge of the mechanisms underpinning the aetiopathogenesis of $\mathrm{AD}$ is imperative for amelioration of symptoms and the institution of targeted prevention and treatment approaches. Current understanding of AD pathogenesis points towards a sophisticated interplay between a genetically determined skin barrier defect, innate and adaptive immune dysregulation with a T-helper 2 cell $\left(\mathrm{T}_{\mathrm{H}} 2\right)$-dominant phenotype, dysbiosis of cutaneous and gut microbiota, as well as environmental risk factors $[5,6]$.

The biological response to the sum of environmental factors an individual is exposed to from conception to death is termed the exposome [7]. It merges the domains of epidemiology, molecular and cellular biology in order to highlight the links between genetics, immunology, microbiology and the environment as it relates to a particular disease. Identifying the pertinent exposome highlights the pathways via which the human and natural environment contribute to disease pathophysiology [8•]. Exposomal enquiry enables modification of pathogenic pathways by altering degrees and timing of exposure to key environmental factors thereby influencing the disease course. Recent advances in molecular biology techniques and a shift in conceptualization has enabled us to broaden our understanding of the biomarkers of disease and the role of distinct environmental factors in pathophysiology [9]. As a consequence, we can measure and analyse the impact of environmental factors common to wider populations (e.g. climate change, migration, urbanization), local communities (e.g. air pollution, water hardness, allergen sensitisation) and individuals (e.g. diet, individual level microbiome alteration, impact of topical and systemic therapy) as they pertain to the aetiopathogenesis of $\mathrm{AD}$. Given the high population prevalence, significant symptom burden, accessibility of the skin as an organ and the resulting exposure to the environment, $\mathrm{AD}$ is uniquely poised for exposomal intervention [10] (Fig. 1-Graphical abstract).

There is a well-established association between $\mathrm{AD}$ and atopic comorbidities, sometimes called the "atopic march", though the relationships between and timing of onset of atopic comorbidities are more complex and many different patterns exist $[11 \bullet \bullet, 12]$. Nonetheless, an enhanced understanding of environmental factors contributing to the pathogenesis of $\mathrm{AD}$ in early life would potentially enable early regulation of the systemic immune response, allergic sensitisation and microbiome dysregulation in an effort to curb development of further atopic comorbidities [13]. In this review, we consider the effects of environmental factors on the skin barrier, immune system and the microbiome in the quest to identify prevention and treatment pathways for potential intervention.

\section{Global population factors}

The exposome has been conceptualized as the sum of external factors (both specific and non-specific) and internal factors (individual level variables such as diet, and by-products of metabolism acting on an individual's internal cellular milieu) that affect an individual from conception to death [7]. We propose an 


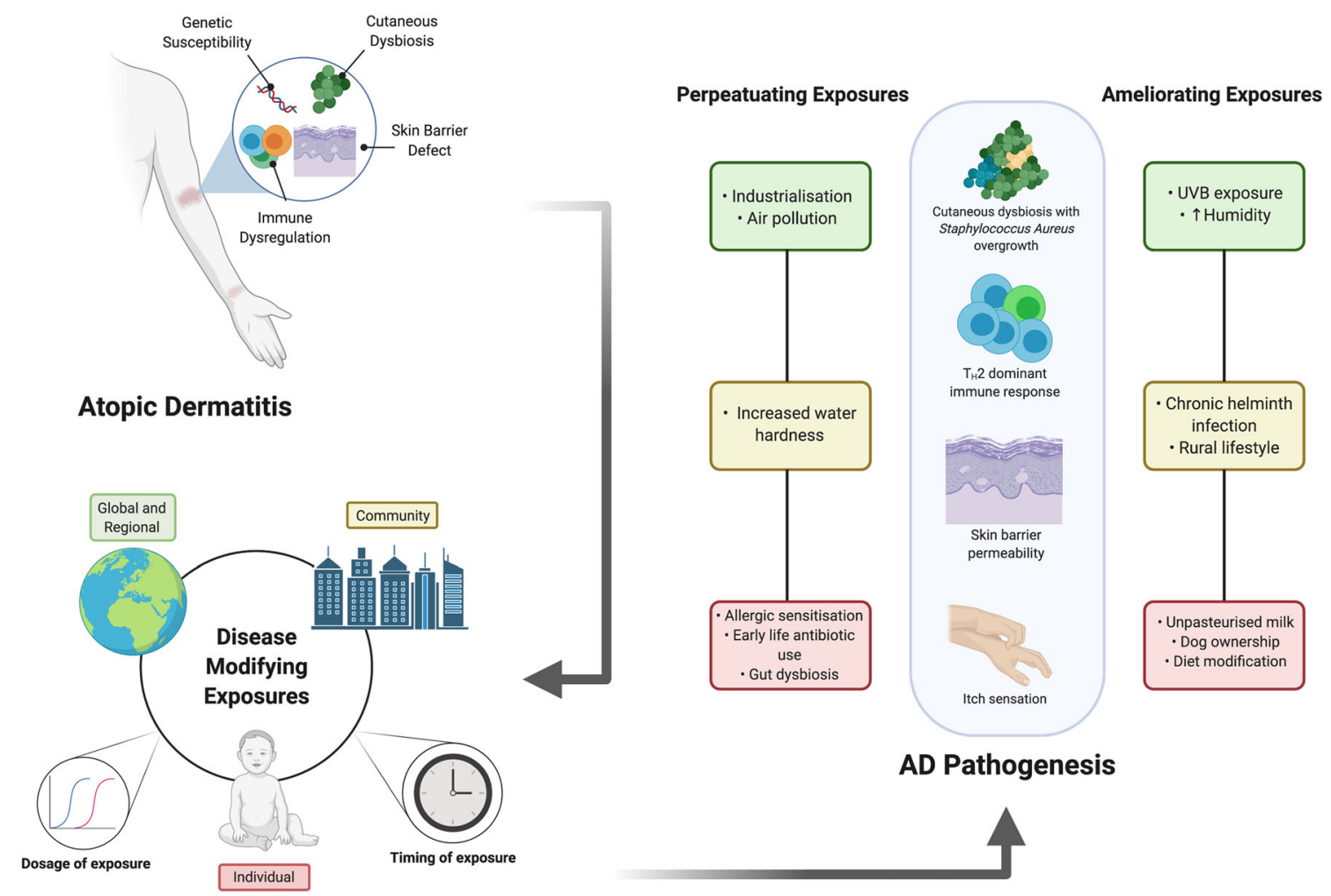

Fig. 1. Graphical abstract. Atopic dermatitis (AD) is a chronic inflammatory condition, affecting up to $20 \%$ of children and up to $5 \%$ of adults worldwide. The pathogenesis of $A D$ is multifactorial, involving genetic susceptibility, skin barrier dysfunction and inflammation as well as microbial dysbiosis. The course of the disease can be modified by external exposures that interact with the above pathogenic pathways and the biological response to such exposures is termed an individual's "exposome". Disease-modifying exposures are common to populations, communities and individuals. An exposomal approach to scientific enquiry enables us to identify the timing and dosage of such exposures in an attempt to either ameliorate disease or its exacerbation, merging the domains of epidemiology with cellular and molecular biology. In this narrative review, we discuss the key external exposures pertinent to $A D$ pathogenesis at the population, community and individual levels and examine their effect on the known perturbations in biologic pathways pertinent to $A D$

alternative model for identifying and modifying environmental exposures based on interventions focused on national and international populations, smaller communities within specific regions and, indeed, individuals themselves.

Differences in lifestyle and population factors associated with industrialization have been linked with a higher prevalence of AD symptoms in the International Study of Asthma and Allergies in Childhood (ISAAC) Phase 1 [14]. Analysis of longitudinal data from ISAAC Phase 3 demonstrated no increase in prevalence in countries that are typically classed as high prevalence, whilst a rise in disease prevalence was demonstrated in low-income settings such as Asia and Latin America, coinciding with changes in lifestyle linked to an increase in industrialization [2]. 
related to global climate change, as increased greenhouse gas emission and rising global temperatures lead to perturbations in humidity and atmospheric UV radiation levels [15]. AD is commoner in areas of low relative humidity, low outdoor temperatures, low levels of ultraviolet (UV) light exposure and in-

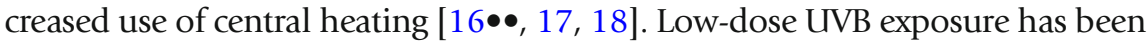
demonstrated to accelerate epidermal skin barrier recovery, synthesize antimicrobial peptides and lipids as well as increase expression of 1-alpha hydroxylase in mouse models [19]. In the presence of UV light, the filaggrin breakdown product (FBP) trans-urocanic acid is converted to the immunosuppressive cisurocanic acid, which in mouse models has been demonstrated to reduce epidermal inflammation with a lower mast cell infiltrate and reduced serum IgE concentration [20]. The cutaneous microbiome is altered by UV radiation in a dose-dependent manner and may contribute to reduced dysbiosis and colonization by superantigen-producing species, such as Staphylococcus aureus, which consequently leads to an influx of $\mathrm{T}_{\mathrm{H}} 2$ cells, IL- 4 and IL-13 production and further recruitment of histamine-producing mast cells and eosinophils [21, $22 \bullet$. Recent evidence also points towards a role of cutaneous UVB exposure in increasing gut microbiome diversity via increased hydroxylation of vitamin $\mathrm{D}$ in the skin-gut microbiota axis [23]. Of particular significance, bacteria from families Lachnospiraceae and Ruminococcus were more abundant in faecal samples of study subjects following low-dose cutaneous UVB exposure. The relative deficiency of the above bacterial families in faecal samples from infants with $\mathrm{AD}$ has been demonstrated to be associated with reduced expression of host immunity-regulating genes [24]. Low relative humidity in regions of high $\mathrm{AD}$ prevalence likely exacerbates the above pathways via reduction of filaggrin expression and enhanced deimination of filaggrin to natural moisturizing factor (NMF), further perturbing the skin barrier $[25,26]$. The above findings may at least partially explain the increased susceptibility to AD flares during cold and dry periods of the year [18].

Alongside climate change, increased levels of air pollution have been demonstrated to correlate positively with AD symptoms [27]. Air pollutants comprising volatile organic compounds (VOC), particulate matter (PM), traffic related air pollution (TRAP) and tobacco smoke have been demonstrated to have a detrimental effect on skin barrier integrity via generation of reactive oxygen species (ROS), as well as epigenetic modification of the immune system in utero, polarizing the adaptive immunity towards a $\mathrm{T}_{\mathrm{H}} 2$ phenotype. This subsequently predisposes infants towards a proinflammatory cutaneous immune profile in the early postnatal period $[28,29]$. Skin barrier disruption is likely facilitated via reduced expression of epidermal structural proteins (filaggrin, cytokeratin, E-cadherin) in response to PM application, whilst exposure to VOC has been demonstrated to increase transepidermal water loss (TEWL) via a yet unidentified mechanism [30,31]. The immune system is likely primed via activation of aryl hydrocarbon receptor (AhR) and nuclear factor kappa B (NFkB) signalling, leading to granulocyte infiltration, perpetuating inflammation [27]. AhR signalling has also been demonstrated to induce hypersensitivity to pruritus via enhanced production of the neurotrophic factor artemin in a mouse model [32]. Exposure to PM may further exacerbate AD by leading to 
cutaneous dysbiosis, as exposure has been demonstrated to enhance cutaneous S. Aureus colonization in animal models [33]. The evidence for tobacco smoke pinpoints to an interplay between epigenetic mechanisms occurring in utero, whereby exposure in the third trimester of pregnancy is correlated with an $\mathrm{AD}$ phenotype in early infancy, likely through epigenetic priming of the immune phenotype towards a $\mathrm{T}_{\mathrm{H}} 2$-dominated skew, as well as further direct damage to the epidermal proteins in the early postnatal period $[34,35]$. The role of air pollution in $\mathrm{AD}$ flares has been supported by several epidemiological studies. A large South Korean cohort study demonstrated a positive correlation between exposure to higher annual mean levels of fine $\mathrm{PM}$ and $\mathrm{NO}_{2}$ and prevalence of $\mathrm{AD}$ symptoms [36]. Short-term elevations in fine and coarse PM were demonstrated to induce $\mathrm{AD}$ flares. Bakeout of VOCs has been separately shown to be an effective technique in reducing $\mathrm{AD}$ symptom burden by minimizing indoor air pollution [37, 38]. Given the links between increasing airborne pollution and $\mathrm{AD}$ prevalence, it is pertinent that population-, community- and individual-level interventions are implemented in an effort to prevent the development of $\mathrm{AD}$ and ameliorate symptoms. Changes in traffic demand during the COVID-19 pandemic have decreased environmental $\mathrm{NO}_{2}$ levels by up to $30 \%$ [39]. The effect of this unprecedented environmental change on $\mathrm{AD}$ prevalence remains to be studied but may provide further insight on the impact of airborne pollution, particularly TRAP in AD. Given the challenges facing population-level interventions to prevent climate change and worsening global pollution, it is imperative that a multifaceted exposomal approach is taken. Individual-level approaches such as barrier restoration with emollients and antioxidants, as well as personal avoidance of exposure to high levels of pollution (where possible) may be adopted as a complementary strategy [40].

\section{Community and regional environmental factors}

Whilst factors such as urbanisation, pollution and climate change affect populations globally, certain disease-modifying environmental exposures affect specific regions within individual countries and their resident communities. Crosssectional and cohort studies have demonstrated an increased prevalence of $\mathrm{AD}$ symptoms in areas with increased levels of water hardness, although no definitive relationship was reported for chlorine [41, 42]. Data from the Enquiring About Tolerance (EAT) study demonstrated a three-fold increased risk of AD development in infants with FLG mutations, as well as a $23.2 \%$ increase in TEWL in infants with FLG mutations exposed to hard water, even without AD [43•]. Current understanding of the mechanisms underpinning this point towards barrier disruption. Hard water increases epidermal deposition of sodium lauryl sulphate (SLS); a detergent commonly present in commercially available washing products [44]. It is thought that SLS deposition decreases profilaggrin expression, with subsequent reduction in NMF and up-regulation of protease activity $[45,46]$. An interventional study is ongoing in the UK, aimed at examining whether installation of a water softener before birth is able to prevent skin barrier breakdown and AD development [47].

Helminth infections are endemic to regions of South America, Africa and Asia. It is postulated that chronic helminthic infection modulates immunity by inducing $\mathrm{T}_{\text {reg }}$ cells and IL-10 production, thereby dampening the $\mathrm{T}_{\mathrm{H}} 2$-skewed 
immune response and conferring a degree of protection against atopic disorders $[48,49]$. Consequently, upon treatment of the helminthic infection, an atopic phenotype is manifested by the $\mathrm{T}_{\mathrm{H}} 2$-primed immune system. Crucially, the timing of infection and its eradication is important. Evidence from a placebocontrolled trial in Uganda demonstrated increased incidence of AD in offspring of women who received treatment with albendazole in the third trimester of pregnancy, whilst a separate study from Vietnam found no increased prevalence of $\mathrm{AD}$ when antihelminthic treatment was instituted in early childhood [50, 51].

\section{Individual risk factors}

Recent data points towards intrinsic inter-individual heterogeneity in AD severity, onset, response to therapy and the implicated molecular mechanisms also known as endotypes [52•]. $\mathrm{T}_{\mathrm{H}} 2$ immune predominance is seen across all endotypes; however, the relative preservation of barrier function and the modulation of additional adaptive immune pathways such as $\mathrm{T}_{\mathrm{H}} 1, \mathrm{~T}_{\mathrm{H}} 17$ and $\mathrm{T}_{\mathrm{H}} 22$, as well as serum IgE levels, appear to be influenced by age and ethnicity [52•, 53]. Disease progression and the development of atopic multimorbidity are associated with younger age of AD onset, parental history of atopy, filaggrin mutations and allergic polysensitisation, as well as living in an urban environment [12]. An exposomal approach would examine an individual's biological and chemical exposures at distinct timepoints throughout their life and their concerted effect on immunity, barrier function and the microbiome. Such an approach (although not currently widely employed due to technical limitations) complements current knowledge of $\mathrm{AD}$ endotypes, enabling specific intervention as part of a personalised therapeutic approach.

A defective skin barrier is thought to be an early initiating factor in the progression to atopic multimorbidity, with earlier age at initial AD diagnosis correlating strongly to food allergen sensitisation $[54,55 \bullet$. Inheritance of FLG loss-offunction mutations in $\mathrm{AD}$ is associated with an earlier age of onset, suggesting a link for gene-environment interaction in allergic sensitisation [56]. Once sensitised, further transepidermal exposure to food and aeroallergens allergens perpetuates inflammation, contributing to chronicity of inflammation. Evidence in support of this theory comes from a study of topical exposure of sensitised individuals to grass pollen, which demonstrated worsening AD symptoms and elevated serum levels of key $\mathrm{T}_{\mathrm{H}} 2$ cytokines following exposure [57]. A recent study by Leonard et al. highlighted four distinct allergen endotypes (food, seasonal, perennial, mixed) in individuals with $A D$ and demonstrated a specific inflammatory signature upregulated in each type [58]. Furthermore, they highlighted an upregulated IgE response to $S$. aureus toxic shock syndrome toxin-1 in subjects displaying perennial and seasonal endotypes, suggesting a link between persistent topical allergen exposure and cutaneous dysbiosis. A systematic review by Tsakok and colleagues linked increasing $\mathrm{AD}$ chronicity and severity in infants with food sensitisation and allergy, with $\mathrm{AD}$ symptoms commonly preceding those of food allergy, 
indicating a causal relationship [59]. Epidemiological findings from the Canadian Longitudinal Healthy Infant Study (CHILD) highlighted that infants with $\mathrm{AD}$ who were poly-sensitised to multiple airborne and food allergens by 3 years of age were at higher risk of developing allergic comorbidities, compared with infants with $\mathrm{AD}$ who were mono-sensitised or non-sensitized [60]. Taken together, the above findings suggest that sensitisation to perennial and seasonal allergens occurs across the skin barrier, can perpetuate $\mathrm{AD}$ chronicity and barrier impairment, consequently leading to polysensitisation and the development of allergic multimorbidity.

\section{Epidermal barrier restoration}

Given the ubiquitous prevalence of topical aeroallergens such as grass pollen and house dust mites in the environment, allergen avoidance may not be a feasible strategy for individual-level intervention. An alternative approach aimed at reducing dysbiosis and restoring the epidermal barrier must therefore be adopted. Recent data from the Barrier Enhancement for Eczema Prevention (BEEP) trial of 1394 infants has shown that daily emollient use from birth in the first year of life has not been effective in preventing the development of $\mathrm{AD}$ and may indeed confer an increased risk of skin infection, despite being a simple and cost-effective intervention [61, 62••]. The mechanism underpinning this may be attributed to the theory of defective extracellular lipid synthesis and delivery due to an underlying genetic predisposition, leading to increased TEWL and structural perturbation of the "bricks and mortar" of the stratum corneum [63]. As a result, the defective structure enables enhanced permeability to allergens and dysbiotic bacteria, triggering the $\mathrm{T}_{\mathrm{H}} 2$-polarised immune response. Topical emollients form an occlusive barrier on the skin surface and provide symptomatic relief but do not correct the underlying molecular defect. Further investigation into physiologic lipid-based barrier restoration therapy in $\mathrm{AD}$ is therefore warranted despite promising early trials [64]. New data from the EAT study suggests that there is a dose-response relationship between emollient application frequency and subsequent development of food allergy (Reference in press, JACI 2020). The mechanism behind this most likely involves transcutaneous sensitisation through regular contact of parents' hands with their child's skin, as they apply the emollient. Nevertheless, a positive role of emollients and their therapeutic utility may lie in the regulation of the cutaneous microbiome. The defective skin barrier contributes to an increased stratum corneum $\mathrm{pH}$, which subsequently promotes growth of $S$. aureus and Streptococcus pyogenes species, with diminished Corynebacterium and Staphylococcus epidermidis populations $[65,66]$. Emollient therapy has been demonstrated to lower skin $\mathrm{pH}$ and restore microbial diversity, particularly with Streptococcus salivarius populations [67]. Increased skin $\mathrm{pH}$ further impairs the cutaneous barrier in a kallikrein-5dependent manner, via thymic stromal lymphopoietin 2 secretion and $\mathrm{T}_{\mathrm{H}} 2$ cell chemotaxis, making acid-base balance restoration a lucrative target for therapy [68].

\section{Modulation of skin and gut microbiota}

Skin and gut microbiota are particularly susceptible to external influences and modification at the individual level, given their interface between an individual's internal milieu and the external environment [69••]. The healthy skin 
microbiome is topographically diverse and dominated by four main phyla-Bacteroidetes, Firmicutes, Actinobacteria and Proteobacteria [6]. The neonatal cutaneous and gut microbiome is influenced by the mode of delivery in the first instance, with caesarean section delivery conferring a microbiome enriched in Staphylococcus spp., whilst infants delivered vaginally have a cutaneous and meconium microbiome colonised by Lactobacilli and Prevotella species [70]. Following delivery, the skin microbiome is rapidly colonised by commensals, tolerance to which is induced via an influx of $\mathrm{T}_{\text {reg }}$ cells into the epidermal comparment [71]. In $\mathrm{AD}$, both lesional and non-lesional skin shows reduced commensal diversity and increased abundance of Staphylococcus species, in particular $S$. aureus [72]. The mechanisms contributing to dysbiosis are multifactorial and include disturbance in skin $\mathrm{pH}$, environmental humidity and temperature changes, as well as other external factors such as frequent antibiotic use alter the composition of skin commensal populations [73]. Consequently, production of antimicrobial peptides (AMP) by commensals such as S. epidermidis is reduced, leading to increased colonisation by S. aureus [74]. S. aureus is a potent inducer of $\mathrm{T}_{\mathrm{H}} 2$ lymphocyte and mast cell chemotaxis, as well as a producer of several toxins and superantigens that have a directly damaging effect on keratinocytes and the epidermal barrier [75•, 76•]. The consequent inflammation perturbs the skin barrier and inhibits the production of AMPs, facilitating an enhanced cycle of dysbiosis [75•, 77]. Perturbation of the skin barrier enhances $S$. aureus colonisation, as a reduction in NMF levels due to abnormal filaggrin metabolism facilitates expression of bacterial clumping factor B, enabling enhanced adhesion to damaged corneocytes [78, 79].

Individual-level interventions may therefore be targeted at restoring microbial diversity on the skin surface. Bacterial diversity may be restored by conventional $\mathrm{AD}$ treatments such as emollient and topical corticosteroid use [80, 81]. More novel approaches include cutaneous microbiota transplants and promotion of increased nature-relatedness, whereby microbial diversity is modulated by frequent close contact with nature on an individual level [82-84]. Dog ownership and direct dog exposure, for instance, have been demonstrated in epidemiological studies to confer a protective effect on AD symptom development, likely in a microbiome-dependent fashion but potentially also via modulation of psychological stress levels and neuroinflammation $[85,86]$.

The gut microbiome represents an alternative niche that may be primed for modulation in $\mathrm{AD}$ therapy, with a view to ameliorating disease. We have previously discussed a link between the natural environment and gut dysbiosis in $\mathrm{AD}$ via a vitamin $\mathrm{D}$-dependent pathway. Infants with $\mathrm{AD}$ are more likely to possess a dysbiotic gut microbiome, with a reduction in short-chain fatty acid (SCFA)-producing species (particularly Bifidobacterium) and an disproportionate increase in Bacteroidetes, Firmicutes and Proteobacteria [87]. This risk may be compounded by the delivery method, as infants born via caesarean section have demonstrably reduced bacterial diversity at 3 months of age. A recent paper from the EAT study suggested that infants with an increased abundance of Clostridium census stricto species in the stool at 3 months are at higher risk of developing $\mathrm{AD}$ [88]. In the above study, bacterial diversity and maturation were increased by early introduction of solid foods into the diet, highlighting a potential strategy for gut microbiome manipulation in at-risk infants. Reduced gut bacterial diversity is hypothesised to contribute to $\mathrm{AD}$ pathogenesis via regulation of systemic immunity, the so-called skin-gut axis (Fig. 2-gut-skin 


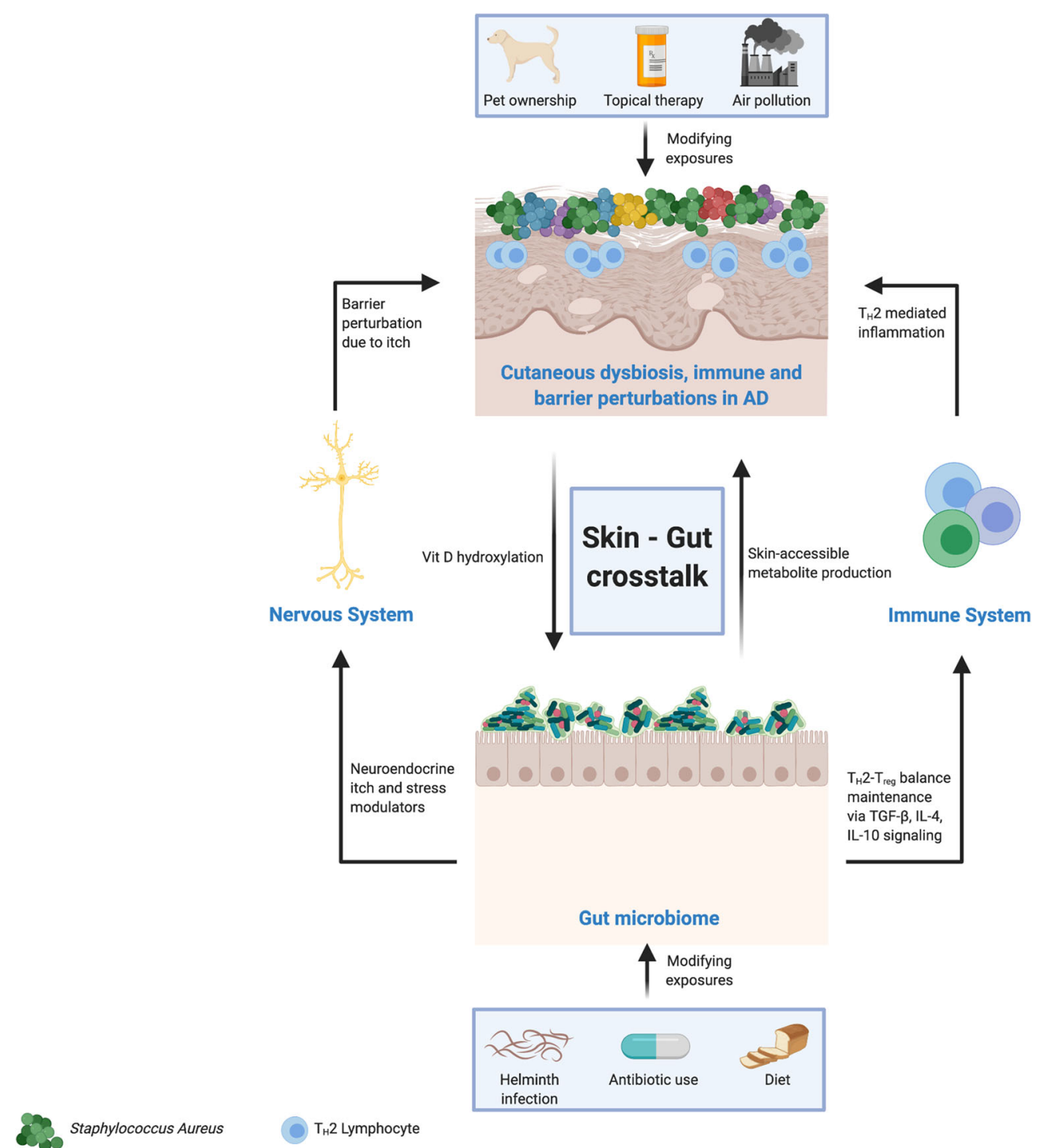

Fig. 2. The role of the skin-gut microbiome axis in atopic dermatitis (AD). The skin and gut microbiota are linked via a number of indirect metabolic pathways, with consequent alterations in both microbiome niches. Animal research suggests that certain gut microbial metabolites may be rendered skin-accessible and have an effect on the cutaneous microbiome, whilst the gut microbiome may be modified via a vitamin D hydroxylation in the skin. In addition, gut bacterial dysbiosis has an effect on the skin immune system via a systemic imbalance in the TH2-Treg lymphocyte ratio, further compounding the aberrant type 2 immune response seen in $\mathrm{AD}$. Furthermore, gut bacteria secrete neuroendocrine itch mediators and a dysbiotic gut perpetuates pruritus, further disrupting the skin barrier and facilitating the overgrowth of Staphylococcus aureus in the skin. Both the cutaneous and gut microbiota are susceptible to modification via external exposures, and the timing and dosage of such exposures are important in maintaining a state of health rather than disease

microbiota crosstalk. Bacterial diversity is crucial for the maturation of $\mathrm{T}_{\mathrm{H}} 1$ and $\mathrm{T}_{\text {reg }}$ pathways, whilst suppressing the aberrant $\mathrm{T}_{\mathrm{H}} 2$-driven immune response that contributes to $\mathrm{AD}$ pathogenesis $[89,90]$. Current knowledge of the mechanisms underlying skin-gut crosstalk largely focuses on the $\mathrm{T}_{\text {reg- }}-\mathrm{T}_{\mathrm{H}} 2$ balance. Experimental evidence from murine models has demonstrated re-programming 
of $\mathrm{T}_{\text {reg }}$ cells into $\mathrm{T}_{\mathrm{H}} 2$ cells via reduced TGF- $\beta$ signalling as a result of expanded innate lymphoid cell 2 (ILC2) populations and IL-4 signalling in the dysbiotic gut [91]. ILC2 cells in skin have also been shown to be expanded in the AD patient population [92]. Conversely, enhanced TGF- $\beta$ signalling following oral supplementation with Lactobacillus strains (which are reduced in the gut microbiome of patients with AD) has been shown to expand the $T_{\text {reg }}$ population, thereby contributing to normal age-related maturation of the adaptive immune system [93•]. An alternative hypothesis postulates that alongside regulating systemic immunity, metabolites from gut microbiota and/or the diet are skin accessible [94]. The evidence in support of this hypothesis largely comes from studies on SCFAs. Experimental evidence has demonstrated inhibition of $S$. Aureus growth by propionic acid produced by Propionibacterium acnes and topical application of butyrate (normally produced in the gut by SCFA producing species) expanded the local cutaneous $\mathrm{T}_{\text {reg }}$ population [95, 96]. Early-life oral antibiotic use (which varies significantly between different countries) is associated with a higher prevalence of AD symptoms, likely through their effect on the gut microbiome and the gut-skin microbiome axis. Maternal antimicrobial use during late pregnancy is also associated with higher AD prevalence in offspring $[97,98]$.

The gut microbiome and consequently gut-skin crosstalk and immunity may be amenable to modulation via dietary modification. A Western diet high in transfatty acids has been associated with increased AD prevalence in ISAAC Phase One, although the precise mechanism contributing to the above observation remains to be elucidated [99]. Certain elements of the rural lifestyle, particularly consumption of unpasteurised milk, have been linked with reduced prevalence of AD symptoms [100]. Indeed, evidence from the genetically homogenous but socioeconomically disparate region of Karelia, which spans the Finnish-Russian border, demonstrated lower prevalence of allergic disorders in the nonWesternised Russian region, which correlated closely with increased Acinetobacter diversity and abundance in populations living in the region [101]. Data from the Promotion of Breastfeeding Intervention Trial (PROBIT) and ISAAC Phase 2 highlighted that breastfeeding (but not prolonged or exclusive breastfeeding) confers a protective effect against AD in early-life $[102,103 \bullet \bullet, 104]$. The mechanisms underpinning the above epidemiological associations may be associated with transfer of microbiota from either unpasteurised milk or breastmilk to the infant, or, alternatively the transfer of soluble immunoactive mediators such as TGF- $\beta$ and IgA [105-107]. Alongside the type of exposure, timing of exposure is likely to be crucial. Antenatal exposure to farm animals and a maternal diet rich in n-3 poly-unsaturated fatty acids have both been demonstrated to reduce the incidence of $\mathrm{AD}$ in the offspring via regulation of foetal immunity and potential microbiotal alterations (e.g. via transplacental passage of microbial metabolites), whilst a diet high in n-6 poly-unsaturated fatty acids had the inverse effect [106, 108, 109]. There is no evidence for dietary probiotic supplementation with Lactobacillus and Bifidobacteria species in treating established AD. However, their use does appear to reduce the relative risk of $\mathrm{AD}$ in offspring when used by women in the last trimester of pregnancy and the infant prior to the development of $\mathrm{AD}[110$, 
$111 \bullet \bullet, 112]$. The evidence for pre-biotics is currently sparse, with improvements in $\mathrm{AD}$ severity demonstrated following dietary supplementation with ketose in one trial of 29 participants, whilst a separate trial of mixed galactooligosaccharides found no evidence of symptomatic improvement [113, 114]. A systematic review of pre-biotics for the prevention of $\mathrm{AD}$ in infants did not find their effect to be significant for risk reduction [115].

\section{Psychological and neuromodulatory influences}

There is great inter-individual variability in the neurally mediated responses to psychological stress and subsequent $\mathrm{AD}$ flares [116]. The converse also holds true, with recent evidence demonstrating a higher incidence of later life behavioural problems in children with $\mathrm{AD}$ [117]. The latter may be explained in part by an immuno-psychiatric hypothesis, stemming from an enhanced understanding of immune processes in regulating CNS homeostasis and individual resilience [118] (Fig. 3-neuroimmune interactions in $\mathrm{AD}$ ). An overactive immune system is thought to increase brain vulnerability, which in turn, coupled with a "second hit" in later life, manifests as neuropsychiatric disorders. Experimental evidence has linked peripheral $\mathrm{T}_{\mathrm{H}} 1 / \mathrm{T}_{\mathrm{H}} 17$ lymphocyte subset expansion to the development of psychosis and bipolar affective disorder in later life; however, evidence regarding the neuropsychiatric sequelae of $\mathrm{T}_{\mathrm{H}}$ 2-skewed immunity is currently sparse $[119,120]$. The biological mechanisms underpinning the response to psychological stress in $\mathrm{AD}$ involve a secretion of neuroendocrine modulators and cutaneous pruritoceptor sensitisation leading to a chronic itch-scratch cycle and thus barrier disruption. Psychological stress induces a central stress response via the hypothalamic-pituitary-adrenal (HPA) axis, leading to glucocorticoid and substance $\mathrm{P}$ secretion. This consequently translates into a systemic neuroimmune response with resulting $\mathrm{T}_{\mathrm{H}} 2$ skew and mast cell priming [121]. In the epidermis, the $\mathrm{T}_{\mathrm{H}} 2$ skewed immune system acts in concert with keratinocytes to create a feed-forward loop of pruritus, mediated primarily by non-histaminergic pruritoceptive $\mathrm{C}$ fibres. Cytokines secreted by $\mathrm{T}_{\mathrm{H}} 2$ cells bind to their respective pruritoceptors on said fibres, as well as exerting the direct stimulating effect of IL4 and IL-13 on keratinocytes to produce thymic stomal lymphopoietin (TSLP). TSLP consequently feeds-forward, promoting ongoing cytokine secretion by $\mathrm{T}_{\mathrm{H}} 2$ lymphocytes, as well as directly binding to its own pruritoceptor [122].One of the critical $\mathrm{T}_{\mathrm{H}} 2$-secreted itch mediators is IL-31. Its secretion has been demonstrated to induce scratching behaviours in multiple animal models, while IL-31 receptor blockage via monoclonal antibody has been deemed efficacious in ameliorating pruritus in clinical $\mathrm{AD}$ trials $[123,124]$. A recent mouse model study of $\mathrm{AD}$ has also highlighted that photoablation of IL-31 receptors on pruritogenic neurons following selective targeting with a ligand resulted in long term reduction in pruritus and selective retraction of pruritogenic neurons from the skin [125]. The keratinocyte injury as a result of mechanical trauma from scratching induces further inflammatory signalling and thereby amplifies the cycle, often until a state of neuronal sensitisation is attained and even a minimal pruritogenic stimulus results in hyper-acute perception of itch [126•]. The chronic itchscratch cycle contributes to anxiety, perpetuating psychological distress and resulting in the aforementioned neuro-immune sequelae, alongside further disruption of the skin barrier [116, 127]. The most promising novel therapies aimed at breaking the itch-scratch cycle in $\mathrm{AD}$ target primarily the type 2 cytokine and IL- 


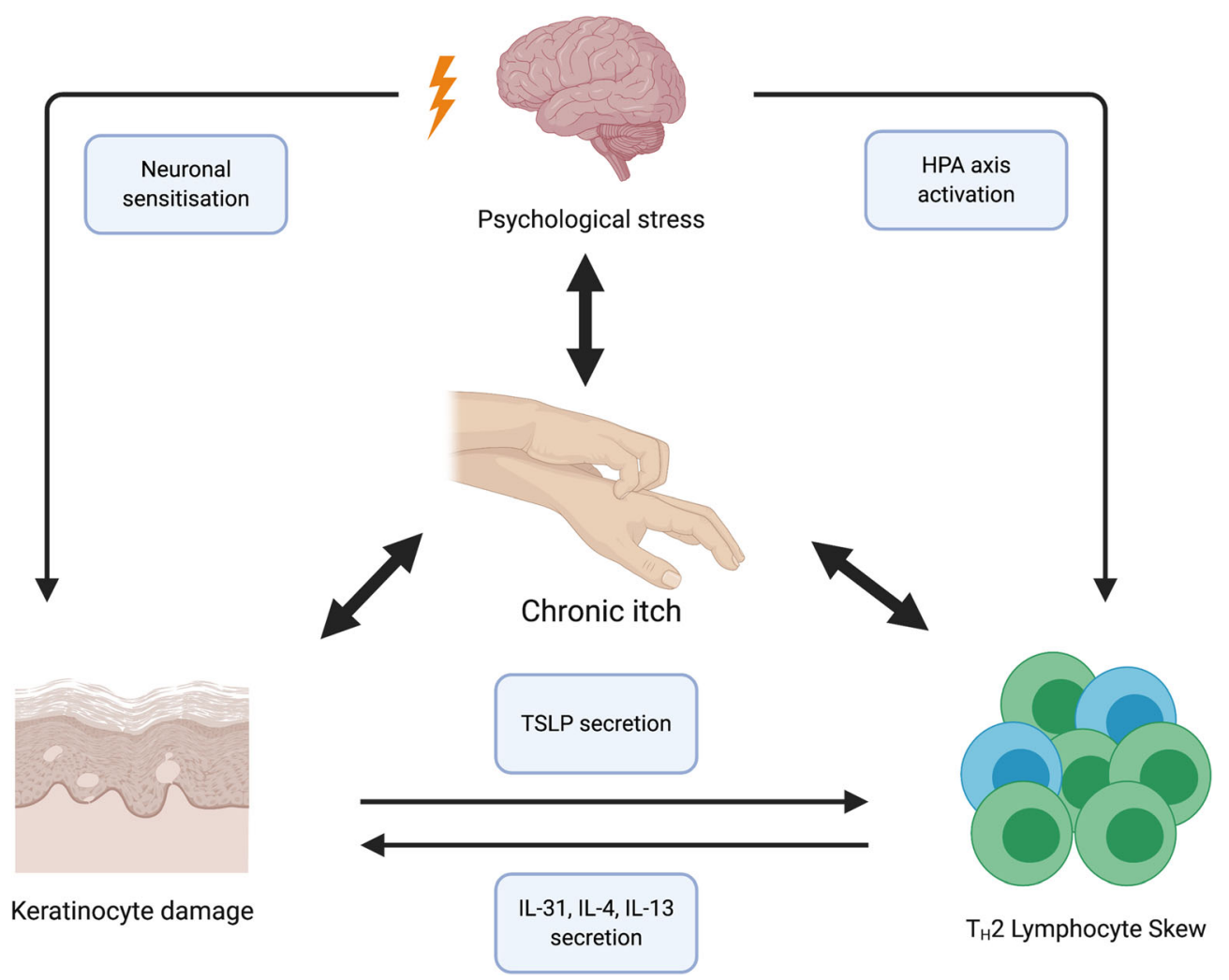

Fig. 3. The interplay of the central nervous, immune and cutaneous systems in atopic dermatitis (AD). The multi-directional interactions of the central nervous (CNS), systemic immune systems and the AD lesional skin are complex. Psychological stress may lead to a TH2-dominant peripheral lymphocyte phenotype via activation of the hypothalamic-pituitary-adrenal (HPA) axis. Consequently, the secretion of TH2 cytokines, in particular IL-31, IL-4 and IL-13, damages cutaneous keratinocytes through persistent inflammation, leading to the secretion of thymic stromal lymphopoietin (TSLP) by keratinocytes and further expanding the TH2 population, thereby creating a feed-forward loop. The above pathways are further compounded by the key AD symptom of chronic itch. Chronic itch not only perpetuates psychological distress, often leading to its chronicity and an impact on lifestyle, but ultimately damages the keratinocytes and leads to cutaneous nervous sensitisation, whereby a minimal pruritogenic stimulus produces an excessive pruritic response

31 signalling pathways and have been reviewed in detail elsewhere [126•]. Emerging evidence also suggests that the gut microbiome may play a role in indirectly modulating the itch-scratch cycle. Lactobacilli and Bifidobacteria produce $\gamma$-aminobutyric acid (GABA) - a central nervous system inhibitory neurotransmitter acting downstream of the pruritoceptive C-fibre pathway, thereby ameliorating skin itch [128]. The gut microbiome is susceptible to alterations in systemic glucocorticoid levels, highlighting the intimate link between the immunobiome, microbiome and psychological stress as a unique individual-specific "internal" exposome domain that may be primed for therapeutic targeting [93•].

The above mechanisms may contribute to a lasting systemic effect, encompassing immune dysregulation, neuropsychiatric comorbidity and $\mathrm{AD}$ chronicity. For instance, it is well established that sleep disturbance is prevalent in the $\mathrm{AD}$ patient population, affecting up to $60 \%$ of individuals $[129,130]$. Sleep disturbance may be defined by an imbalance in both sleep continuity 
(total sleep time, sleep fragmentation) and sleep architecture (the ratio of slow wave sleep (SWS) to rapid eye movement (REM) sleep). A recent review has proposed that sleep disturbance is an immunoregulatory response to stress due to environmental threat, the nature of such disturbance being dependent on the acuity or chronicity of said threat [131]. In the modern environment, the threats encountered by individuals are by and large chronic, psychosocial ones as opposed to more immediately threatening adversities such as predators and/ or infectious disease. Patients with AD may have a heightened perception of chronic psychosocial adversity due to their condition, resulting in a limitation

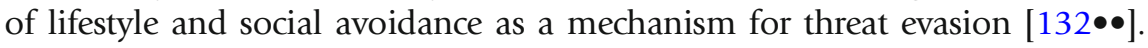
Sleep disturbance in the chronic stress setting (impaired continuity, decrease in the SWS:REM ratio) has been demonstrated to skew the peripheral immune profile towards a $\mathrm{T}_{\mathrm{H}} 2$ phenotype, further perpetuating the immune dysregulation seen in $\mathrm{AD}$ [131]. Managing the psychological component of $\mathrm{AD}$ can therefore be viewed as an integral part of the holistic approach to care in an effort to address the perturbed physiological pathways that underpin AD pathogenesis [133].

\section{Conclusion and future perspectives}

Availability of data and material

Current evidence in AD points towards a sophisticated biological response to environmental exposures at the genetic, immune, microbiome and skin barrier levels. The timing and dosage of exposures is critical when considering modification of environmental factors in primary prevention and therapeutics in AD. Taken together, a holistic exposomal approach requires intervention at the global, community and individual level to ameliorate and potentially prevent disease. While many scientific advances have been made with regard to the nature of the precise biological response to specific environmental triggers, there remain many unknowns and challenges. Modern technology, particularly the use of longitudinal personal monitoring and artificial intelligence, may provide additional insight into the key questions of the "dose-timing response"

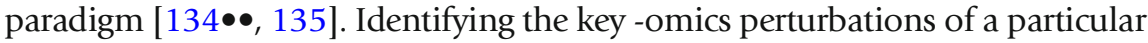
condition and the biomarkers associated with such perturbations may enable clinicians to pinpoint distinct phenotypes within a particular condition, subsequently targeting appropriate prevention and therapeutic pathways and move further into the realm of personalised medicine.

Not applicable.

Code availability

Not applicable.

\section{Declarations}

Ethics approval

Not applicable. 


\section{Consent to participate}

Not applicable.

\section{Consent for publication}

Not applicable.

\section{Conflict of interest}

Nicholas Stefanovic has nothing to disclose.

Alan D. Irvine reports and Consultancy- AbbVie, Arena Pharmaceuticals, BenevolentAI, Chugai, Dermavant, Genentech, LEO Pharma, Lilly, Menlo Therapeutics, Novartis, Pfizer, Regeneron, Sanofi, and UCB..

Carsten Flohr is chief investigator of the UK National Institute for Health Research-funded TREAT (ISRCTN15837754) and SOFTER (Clinicaltrials.gov: NCT03270566) trials as well as the UK-Irish Atopic eczema Systemic Therapy Register (A-STAR; ISRCTN11210918) and a principal investigator in the European Union Horizon 2020-funded BIOMAP Consortium (http://www.biomap-imi.eu/). His department has also received funding from Sanofi-Genzyme.

\section{Human and animal rights and informed consent}

This article does not contain any studies with human or animal subjects performed by any of the authors.

Open Access This article is licensed under a Creative Commons Attribution 4.0 International License, which permits use, sharing, adaptation, distribution and reproduction in any medium or format, as long as you give appropriate credit to the original author(s) and the source, provide a link to the Creative Commons licence, and indicate if changes were made. The images or other third party material in this article are included in the article's Creative Commons licence, unless indicated otherwise in a credit line to the material. If material is not included in the article's Creative Commons licence and your intended use is not permitted by statutory regulation or exceeds the permitted use, you will need to obtain permission directly from the copyright holder. To view a copy of this licence, visit http://creativecommons.org/licenses/by/4.0/.

\section{References}

Papers of particular interest, published recently, have been

highlighted as:

- Of importance

$\bullet \quad$ Of major importance

1. Nutten S. Atopic Dermatitis: global epidemiology and risk factors. Ann Nutr Metab. 2015;66:8-16.

2. Odhiambo JA, Williams HC, Clayton TO, et al. Global variations in prevalence of eczema symptoms in children from ISAAC Phase Three. J Allergy Clin Immunol. 2009;124:1251-1258.e23. https://doi.org/10.1016/j. jaci.2009.10.009.

3. Laughter MR, Maymone MBC, Mashayekhi S, Arents BWM, Karimkhani C, Langan SM, et al. The global burden of atopic dermatitis: lessons from the GBD Study - 1990 to 2017. Br J Dermatol. 2020;184:304-9. https://doi.org/10.1111/bjd.19580.

4. Weidinger S, Beck LA, Bieber T, Kabashima K, Irvine AD. Atopic dermatitis. Nat Rev Dis Prim. 2018;4:1.
5. Leung DYM. New insights into atopic dermatitis: role of skin barrier and immune dysregulation. Allergol Int. 2013;62:151-61.

6. Powers CE, McShane DB, Gilligan PH, et al. Microbiome and pediatric atopic dermatitis. J Dermatol. 2015;42:1137-42.

7. Cecchi L, D'Amato G, Annesi-Maesano I. External exposome and allergic respiratory and skin diseases. $J$ Allergy Clin Immunol. 2018;141:846-57.

8. Stefanovic N, Flohr C, Irvine AD. The exposome in atopic dermatitis. Allergy. 2020;75:63-74

Useful literature review providing an in-depth analysis of the exposome as it pertains to atopic dermatitis.

9. Canali S. What is new about the exposome? Exploring scientific change in contemporary epidemiology. Int $J$ 
Environ Res Public Health. 2020;17. https://doi.org/10. 3390/ijerph17082879.

10. Eichenfield LF, Tom WL, Chamlin SL, Feldman SR, Hanifin JM, Simpson EL, et al. Guidelines of care for the management of atopic dermatitis: Section 1. Diagnosis and assessment of atopic dermatitis Work Group. J Am Acad Dermatol. 2014;70:338-51.

11.• Paller AS, Spergel JM, Mina-Osorio P, Irvine AD. The atopic march and atopic multimorbidity: many trajectories, many pathways. J Allergy Clin Immunol. 2018. https://doi.org/10.1016/j.jaci.2018.11.006

This literature review highlights that the classical "atopic march" is but one possibility with regards to progression of AD to atopic multimorbidity and that early life AD phenotypes, genotypes and environmental factors influence overall atopic disease trajectory.

12. Irvine $\mathrm{AD}$, Mina-Osorio P. Disease trajectories in childhood atopic dermatitis: an update and practitioner's guide. Br J Dermatol. 2019;181:895-906.

13. Bantz SK, Zhu Z, Zheng T. The atopic march: progression from atopic dermatitis to allergic rhinitis and asthma. J Clin Cell Immunol. 2014;5. https://doi.org/10. 4172/2155-9899.1000202.

14. Innes Asher M, Stewart AW, Mallol J, et al. Which population level environmental factors are associated with asthma, rhinoconjunctivitis and eczema? Review of the ecological analyses of ISAAC Phase One What was ISAAC Phase One? 2010. https://doi.org/10.1186/ 1465-9921-11-8

15. Nguyen GH, Andersen LK, Davis MDP. Climate change and atopic dermatitis: is there a link? Int J Dermatol. 2019;58:279-82.

16.• Fuertes E, Flohr C, Silverberg JI, et al. Global associations between UVR exposure and current eczema prevalence in children from ISAAC phase three. J Invest Dermatol, 137. 2017:1248-56

This ecological study links variations in global mean ultraviolet radiation exposure with prevalence of $\mathrm{AD}$ across multiple global regions.

17. J.I. S, J.M. H. Relative humidity, dew point, indoor heating and ultraviolet index are associated with the prevalence of eczema. J Invest Dermatol. 2012;132:S44.

18. Hamann CR, Andersen YMF, Engebretsen KA, Skov L, Silverberg JI, Egeberg A, et al. The effects of season and weather on healthcare utilization among patients with atopic dermatitis. J Eur Acad Dermatology Venereol. 2018;32:1745-53. https://doi.org/10.1111/jdv.15023.

19. Hong SP, Kim MJ, Jung MY, Jeon H, Goo J, Ahn SK, et al. Biopositive effects of low-dose UVB on epidermis: coordinate upregulation of antimicrobial peptides and permeability barrier reinforcement. J Invest Dermatol. 2008;128:2880-7.

20. Rieko K-K, Motonobu N. Effect of cis-urocanic acid on atopic dermatitis in NC/Nga mice. J Dermatol Sci. 2016;84:e65-6.

21. Patra VK, Byrne SN, Wolf P. The skin microbiome: Is it affected by UV-induced immune suppression? Front
Microbiol. 2016;7. https://doi.org/10.3389/fmicb. 2016.01235

22. Tsakok T, Woolf R, Smith $\mathrm{CH}$, et al. Atopic dermatitis: the skin barrier and beyond. Br J Dermatol. 2018. https://doi.org/10.1111/bjd.16934

This review outlines the pathogenesis of AD from a skin barrier perspective and highlights how a defective skin barrier interplays with genetics, immunity, the microbiome and the environment.

23. Bosman ES, Albert AY, Lui H, Dutz JP, Vallance BA. Skin exposure to narrow band ultraviolet (UVB) light modulates the human intestinal microbiome. Front Microbiol. 2019;10:2410.

24. Lee M-J, Kang M-J, Lee S-Y, et al. Perturbations of gut microbiome genes in infants with atopic dermatitis according to feeding type Gut microbiome of 6-month infant Feeding type. 2018. doi:https://doi.org/10. 1016/j.jaci.2017.11.045

25. Cau L, Pendaries V, Lhuillier E, Thompson PR, Serre G, Takahara $\mathrm{H}$, et al. Lowering relative humidity level increases epidermal protein deimination and drives human filaggrin breakdown. J Dermatol Sci. 2017;86:106-13.

26. Engebretsen KA, Johansen JD, Kezic S, Linneberg A, Thyssen JP. The effect of environmental humidity and temperature on skin barrier function and dermatitis. J Eur Acad Dermatology Venereol. 2016;30:223-49.

27. Hendricks AJ, Eichenfield LF, Shi VY. The impact of airborne pollution on atopic dermatitis: a literature review. Br J Dermatol. 2020:bjd.18781.

28. Ahn K. The role of air pollutants in atopic dermatitis. $J$ Allergy Clin Immunol. 2014;134:993-9.

29. Liu W, Cai J, Huang C, Hu Y, Fu Q, Zou Z, et al. Associations of gestational and early life exposures to ambient air pollution with childhood atopic eczema in Shanghai, China. Sci Total Environ. 2016;572:34-42.

30. Pan TL, Wang PW, Aljuffali IA, Huang CT, Lee CW, Fang JY. The impact of urban particulate pollution on skin barrier function and the subsequent drug absorption. J Dermatol Sci. 2015;78:51-60.

31. Huss-Marp J, Eberlein-König B, Breuer K, et al. Influence of short-term exposure to airborne Der p 1 and volatile organic compounds on skin barrier function and dermal blood flow in patients with atopic eczema and healthy individuals. Clin Exp Allergy. 2006;36:33845.

32. Hidaka T, Ogawa E, Kobayashi EH, Suzuki T, Funayama R, Nagashima T, et al. The aryl hydrocarbon receptor AhR links atopic dermatitis and air pollution via induction of the neurotrophic factor artemin. Nat Immunol. 2017;18:64-73.

33. Han RT, Kim HY, Ryu H, Jang W, Cha SH, Kim HY, et al. Glyoxal-induced exacerbation of pruritus and dermatitis is associated with staphylococcus aureus colonization in the skin of a rat model of atopic dermatitis. J Dermatol Sci. 2018;90:276-83.

34. Shinohara M, Matsumoto K. Fetal Tobacco smoke exposure in the third trimester of pregnancy is associated 
with atopic eczema/dermatitis syndrome in Infancy. Pediatr Allergy Immunol Pulmonol. 2017;30:155-62.

35. Yi O, Kwon H-J, Kim H, Ha M, Hong SJ, Hong YC, et al. Effect of environmental tobacco smoke on atopic dermatitis among children in Korea. Environ Res. 2012;113:40-5. https://doi.org/10.1016/j.envres. 2011.12.012.

36. Min K-D, Yi S-J, Kim H-C, et al. Association between exposure to traffic-related air pollution and pediatric allergic diseases based on modeled air pollution concentrations and traffic measures in Seoul, Korea: a comparative analysis. Environ Heal. 2020;19:6.

37. Kim EH, Kim S, Lee JH, Kim J, Han Y, Kim YM, et al. Indoor air pollution aggravates symptoms of atopic dermatitis in children. PLoS One. 2015;10:e0119501. https://doi.org/10.1371/journal.pone.0119501.

38. Oh I, Lee J, Ahn K, Kim J, Kim YM, Sun Sim C, et al. Association between particulate matter concentration and symptoms of atopic dermatitis in children living in an industrial urban area of South Korea. Environ Res. 2018;160:462-8.

39. Muhammad S, Long X, Salman M. COVID-19 pandemic and environmental pollution: A blessing in disguise? Sci Total Environ. 2020;728:138820.

40. Valacchi G, Muresan XM, Sticozzi C, Belmonte G, Pecorelli A, Cervellati F, et al. Ozone-induced damage in 3D-Skin Model is prevented by topical vitamin C and vitamin E compound mixtures application. $J$ Dermatol Sci. 2016;82:209-12.

41. Engebretsen KA, Bager P, Wohlfahrt J, et al. Prevalence of atopic dermatitis in infants by domestic water hardness and season of birth: Cohort study. J Allergy Clin Immunol. 2017;139:1568-1574.e1.

42. Perkin MR, Craven J, Logan K, Strachan D, Marrs T, Radulovic S, et al. Association between domestic water hardness, chlorine, and atopic dermatitis risk in early life: a population-based cross-sectional study. J Allergy Clin Immunol. 2016;138:509-16.

43.• Jabbar-Lopez ZK, Craven J, Logan K, et al. Longitudinal analysis of the effect of water hardness on atopic eczema: evidence for gene-environment interaction. $\mathrm{Br} \mathrm{J}$ Dermatol. 2019. https://doi.org/10.1111/bjd.18597

This longitudinal cohort study demonstrates a link between hard water exposure and AD development in FLG loss of function mutation carriers.

44. Danby SG, Brown K, Wigley AM, Chittock J, Pyae PK, Flohr $\mathrm{C}$, et al. The effect of water hardness on surfactant deposition after washing and subsequent skin irritation in atopic dermatitis patients and healthy control subjects. J Invest Dermatol. 2018;138:68-77.

45. Flohr C, Mann J. New insights into the epidemiology of childhood atopic dermatitis. Allergy Eur J Allergy Clin Immunol. 2014;69:3-16. https://doi.org/10.1111/all. 12270.

46. Törmä H, Lindberg M, Berne B. Skin barrier disruption by sodium lauryl sulfate-exposure alters the expressions of involucrin, transglutaminase 1 , profilaggrin, and kallikreins during the repair phase in human skin in vivo. J Invest Dermatol. 2008;128:1212-9.
47. Walters RM, Anim-Danso E, Amato SM, Capone K, Mack MC, Telofski L, et al. Hard water softening effect of a baby cleanser. Clin Cosmet Investig Dermatol. 2016;9:339-45.

48. Flohr C, Quinnell RJ, Britton J. Do helminth parasites protect against atopy and allergic disease? Clin Exp Allergy. 2009;39:20-32.

49. Sanchez AL, Mahoney DL, Gabrie JA. Interleukin-10 and soil-transmitted helminth infections in Honduran children. BMC Res Notes. 2015;8:55. https://doi.org/10. 1186/s13104-015-1019-x.

50. Ndibazza J, Mpairwe H, Webb EL, Mawa PA, Nampijja $\mathrm{M}$, Muhangi $\mathrm{L}$, et al. Impact of anthelminthic treatment in pregnancy and childhood on immunisations, infections and eczema in childhood: a randomised controlled trial. PLoS One. 2012;7:e50325.

51. Flohr C, Tuyen LN, Quinnell RJ, et al. Reduced helminth burden increases allergen skin sensitization but not clinical allergy: a randomized, double-blind, placebo-controlled trial in Vietnam. Clin Exp Allergy. 2009;40:131-42.

52.• Czarnowicki T, He H, Krueger JG, Guttman-Yassky E. Atopic dermatitis endotypes and implications for targeted therapeutics. J Allergy Clin Immunol. 2019;143:1-11

This review highlights the presence of multiple AD "endotypes", based on variation in patient and disease characteristics. This subsequently has implications for personalised therapy and aims to guide clinicians away from the traditional "one size fits all" approach.

53. Kalamaha K, Reis E, Newton S, Roche C, Julson J, Fernandes $\mathrm{H}$, et al. Atopic dermatitis: a review of evolving targeted therapies. Expert Rev Clin Immunol. 2019;15:275-88.

54. Martin PE, Eckert JK, Koplin JJ, Lowe AJ, Gurrin LC, Dharmage SC, et al. Which infants with eczema are at risk of food allergy? Results from a population-based cohort. Clin Exp Allergy. 2015;45:255-64.

55. $\quad$ Lowe AJ, Leung DYM, Tang MLK, et al. The skin as a target for prevention of the atopic march. Ann Allergy, Asthma Immunol. 2018;120:145-51

This narrative review outlines strategies for prevention of atopic multimorbidity via early amelioration of $\mathrm{AD}$ symptoms.

56. Smieszek SP, Welsh S, Xiao C, Wang J, Polymeropoulos C, Birznieks $\mathrm{G}$, et al. Correlation of age-of-onset of atopic dermatitis with filaggrin loss-of-function variant status. Sci Rep. 2020;10:2721. https://doi.org/10.1038/ s41598-020-59627-7.

57. Werfel T, Heratizadeh A, Niebuhr M, et al. Exacerbation of atopic dermatitis on grass pollen exposure in an environmental challenge chamber. J Allergy Clin Immunol. 2015;136:96-103.e9.

58. Leonard A, Wang J, Yu L, et al. Atopic dermatitis endotypes based on allergen sensitization, reactivity to Staphylococcus aureus antigens, and underlying systemic inflammation. J Allergy Clin Immunol Pract. 2020;8:236-247.e3. 
59. Tsakok T, Marrs T, Mohsin M, Baron S, du Toit G, Till S, et al. Does atopic dermatitis cause food allergy? A systematic review. J Allergy Clin Immunol. 2016;137:1071-8. https://doi.org/10.1016/j.jaci.2015. 10.049 .

60. Dharma C, Lefebvre DL, Tran MM, Lou WYW, Subbarao P, Becker AB, et al. Patterns of allergic sensitization and atopic dermatitis from 1 to 3 years: Effects on allergic diseases. Clin Exp Allergy. 2018;48:48-59.

61. Chalmers JR, Haines RH, Mitchell EJ, Thomas KS, Brown SJ, Ridd M, et al. Effectiveness and costeffectiveness of daily all-over-body application of emollient during the first year of life for preventing atopic eczema in high-risk children (The BEEP trial): protocol for a randomised controlled trial. Trials. 2017;18:343.

62.• Chalmers JR, Haines RH, Bradshaw LE, et al. Daily emollient during infancy for prevention of eczema: the BEEP randomised controlled trial. Lancet. 2020;395:962-72

The findings of this randomised controlled trial suggest that there is no evidence for daily emollient use in early life in an aim to prevent $\mathrm{AD}$ development, and may be associated with an increase in skin infections.

63. Elias PM, Sugarman J. Does moisturizing the skin equate with barrier repair therapy? Ann Allergy Asthma Immunol. 2018;121:653-656.e2.

64. Koppes SA, Charles F, Lammers LA, Frings-Dresen M, Kezic S, Rustemeyer T. Efficacy of a cream containing ceramides and magnesium in the treatment of mild to moderate atopic dermatitis: a randomized, doubleblind, emollient- and hydrocortisone-controlled trial. Acta Derm Venereol. 2016;96:948-53.

65. Elias PM. The how, why and clinical importance of stratum corneum acidification. Exp Dermatol. 2017;26:999-1003.

66. Grice EA, Segre JA. The skin microbiome. Nat Rev Microbiol. 2011;9:244-53.

67. Glatz M, Jo J-H, Kennedy EA, et al. Emollient use alters skin barrier and microbes in infants at risk for developing atopic dermatitis. PLoS One. 2018;13:1-17.

68. Jang H, Matsuda A, Jung K, Karasawa K, Matsuda K, Oida K, et al. Skin pH Is the master switch of kallikrein 5-mediated skin barrier destruction in a murine atopic dermatitis model. J Invest Dermatol. 2016;136:127-35.

69.• Prescott SL, Larcombe DL, Logan AC, et al. The skin microbiome: Impact of modern environments on skin ecology, barrier integrity, and systemic immune programming. World Allergy Organ J. 2017. https://doi. org/10.1186/s40413-017-0160-5

This narrative review outlines the impact of alterations in the external environment on cutaneous gut dysbiosis and emphasises the importance of ecological interventions in restoring skin biodiversity.

70. Dominguez-Bello MG, Costello EK, Contreras $M$, Magris M, Hidalgo G, Fierer N, et al. Delivery mode shapes the acquisition and structure of the initial microbiota across multiple body habitats in newborns.
Proc Natl Acad Sci. 2010;107:11971-5. https://doi.org/ 10.1073/pnas.1002601107.

71. Scharschmidt TC, Vasquez KS, Truong HA, Gearty SV, Pauli ML, Nosbaum A, et al. A wave of regulatory T cells into neonatal skin mediates tolerance to commensal microbes. Immunity. 2015;43:1011-21. https://doi. org/10.1016/j.immuni.2015.10.016.

72. Kong HH, Oh J, Deming C, Conlan S, Grice EA, Beatson MA, et al. Temporal shifts in the skin microbiome associated with disease flares and treatment in children with atopic dermatitis. Genome Res. 2012;22:850-9. https://doi.org/10.1101/gr.131029. 111.

73. Nakatsuji T, Gallo RL. The role of the skin microbiome in atopic dermatitis. Ann Allergy Asthma Immunol. 2019;122:263-9.

74. Lai Y, Cogen AL, Radek KA, Park HJ, MacLeod DT, Leichtle A, et al. Activation of TLR2 by a small molecule produced by staphylococcus epidermidis increases antimicrobial defense against bacterial skin infections. J Invest Dermatol. 2010;130:2211-21.

75. Geoghegan JA, Irvine AD, Foster TJ. Staphylococcus aureus and atopic dermatitis: a complex and evolving relationship. Trends Microbiol. 2018. https://doi.org/ 10.1016/j.tim.2017.11.008

This review effectively outlines the pathogenicity of Staphylococcus aureus overgrowth in AD.

76. Alexander H, Paller AS, Traidl-Hoffmann C, et al. The role of bacterial skin infections in atopic dermatitis: expert statement and review from the International Eczema Council Skin Infection Group. Br J Dermatol. 2020;182:1331-42

This narrative review summarises the latest evidence from animal and human studies on the features of bacterial skin infection in $\mathrm{AD}$ and our understanding of host and pathogen factors that influence colonisation by Staphylococcus aureus.

77. Nakatsuji T, Chen TH, Two AM, Chun KA, Narala S, Geha RS, et al. Staphylococcus aureus exploits epidermal barrier defects in atopic dermatitis to trigger cytokine expression. J Invest Dermatol. 2016;136:2192-200.

78. Fleury OM, McAleer MA, Feuillie C, et al. Clumping factor B promotes adherence of Staphylococcus aureus to corneocytes in atopic dermatitis. Infect Immun. 2017;85. https://doi.org/10.1128/IAI.00994-16.

79. Feuillie C, Vitry P, McAleer MA, et al. Adhesion of Staphylococcus aureus to Corneocytes from atopic dermatitis patients is controlled by natural moisturizing factor levels. MBio. 2018;9:e01184-18.

80. Seite S, Flores GE, Henley JB, Martin R, Zelenkova H, Aguilar L, et al. Microbiome of affected and unaffected skin of patients with atopic dermatitis before and after emollient treatment. J Drugs Dermatol. 2014;13:136572.

81. Gonzalez ME, Schaffer JV, Orlow SJ, et al. Cutaneous microbiome effects of fluticasone propionate cream and adjunctive bleach baths in childhood atopic dermatitis. J Am Acad Dermatol. 2016;75:481-493.e8. 
82. Paetzold B, Willis JR, Pereira De Lima J, et al. Skin microbiome modulation induced by probiotic solutions. Microbiome. 2019;7:95.

83. Prescott SL, Larcombe DL, Logan AC, West C, Burks W, Caraballo L, et al. The skin microbiome: impact of modern environments on skin ecology, barrier integrity, and systemic immune programming. World Allergy Organ J. 2017;10:29. https://doi.org/10.1186/ s40413-017-0160-5.

84. Nisbet EK, Zelenski JM, Murphy SA. The nature relatedness scale: linking individuals' connection with nature to environmental concern and behavior. Environ Behav. 2009;41:715-40. https://doi.org/10.1177/ 0013916508318748.

85. Langan SM, Flohr C, Williams HC. The role of furry pets in eczema: a systematic review. Arch Dermatol. 2007;143. https://doi.org/10.1001/archderm.143.12. 1570 .

86. Pelucchi C, Galeone C, ois Bach J-F, et al. Pet exposure and risk of atopic dermatitis at the pediatric age: A meta-analysis of birth cohort studies. 2013. 10.1016/ j.jaci.2013.04.009.

87. Reddel S, Del Chierico F, Quagliariello A, et al. Gut microbiota profile in children affected by atopic dermatitis and evaluation of intestinal persistence of a probiotic mixture. Sci Rep. 2019;9:1-10.

88. Marrs T, Jo JH, Perkin MR, Rivett DW, Witney AA, Bruce KD, Logan K, Craven J, Radulovic S, Versteeg SA, van Ree R, McLean W, Strachan DP, Lack G, Kong HH, Flohr C. Gut microbiota development during infancy: Impact of introducing allergenic foods. The Journal of Allergy and Clinical Immunology. 2021;147(2):613621.e9.

89. West CE, Jenmalm MC, Prescott SL. The gut microbiota and its role in the development of allergic disease: A wider perspective. Clin Exp Allergy. 2015;45:43-53.

90. Abrahamsson TR, Jakobsson HE, Andersson AF, et al. Low diversity of the gut microbiota in infants with atopic eczema. J Allergy Clin Immunol. 2012;129:434440.e2.

91. Noval Rivas M, Burton OT, Oettgen HC, Chatila T. IL-4 production by group 2 innate lymphoid cells promotes food allergy by blocking regulatory T-cell function. J Allergy Clin Immunol. 2016;138:801-811.e9. https:// doi.org/10.1016/j.jaci.2016.02.030.

92. Roediger B, Kyle R, Le Gros G, Weninger W. Dermal group 2 innate lymphoid cells in atopic dermatitis and allergy. Curr Opin Immunol. 2014;31:108-14.

93. Lee SY, Lee E, Park YM, Hong SJ. Microbiome in the gut-skin axis in atopic dermatitis. Allergy, Asthma Immunol Res. 2018;10:354-62

This narrative review outlines the role of the gut and skin microbiota as it pertains to $\mathrm{AD}$ development and introduces the idea of gut-skin crosstalk at the level of the microbiome.

94. O'Neill CA, Monteleone G, McLaughlin JT, Paus R. The gut-skin axis in health and disease: a paradigm with therapeutic implications. BioEssays. 2016;38:1167-76.

95. Schwarz A, Bruhs A, Schwarz T. The short-chain fatty acid sodium butyrate functions as a regulator of the skin immune system. J Invest Dermatol. 2017;137:85564.

96. Shu M, Wang Y, Yu J, Kuo S, Coda A, Jiang Y, et al. Fermentation of Propionibacterium acnes, a commensal bacterium in the human skin microbiome, as skin probiotics against methicillin-resistant Staphylococcus aureus. PLoS One. 2013;8:e55380.

97. Pascal M, Perez-Gordo $M$, Caballero T, Escribese MM, Lopez Longo MN, Luengo O, et al. Microbiome and Allergic Diseases. Front Immunol. 2018;9:1584.

98. Timm S, Schlünssen V, Olsen J, Ramlau-Hansen CH. Prenatal antibiotics and atopic dermatitis among 18month-old children in the Danish National Birth Cohort. Clin Exp Allergy. 2017;47:929-36.

99. Ellwood P, Asher MI, Björkstén B, Burr M, Pearce N, Robertson $\mathrm{CF}$, et al. Diet and asthma, allergic rhinoconjunctivitis and atopic eczema symptom prevalence: an ecological analysis of the International Study of Asthma and Allergies in Childhood (ISAAC) data. ISAAC Phase One Study Group. Eur Respir J. 2001;17:436-43.

100. Perkin M, Strachan D. Which aspects of the farming lifestyle explain the inverse association with childhood allergy? J Allergy Clin Immunol. 2006;117:137481.

101. Ruokolainen L, Paalanen L, Karkman A, Laatikainen $\mathrm{T}$, von Hertzen L, VlasoffT, et al. Significant disparities in allergy prevalence and microbiota between the young people in Finnish and Russian Karelia. Clin Exp Allergy. 2017;47:665-74.

102. Kramer MS, Chalmers B, Hodnett ED, et al. Promotion of Breastfeeding Intervention Trial (PROBIT): a randomized trial in the Republic of Belarus. JAMA. 285:413-20.

103.• Flohr C, Henderson AJ, Kramer MS, et al. Effect of an Intervention to Promote Breastfeeding on Asthma, Lung Function, and Atopic Eczema at Age 16 Years. JAMA Pediatr. 2018;172:e174064

This paper outlines the results of the Promotion of Breastfeeding Intervention Trial (PROBIT) on atopic dermatitis and reports that a breastfeeding intervention reduces the incidence of flexural dermatitis risk, but does not affect questionnaire derived measures of atopic dermatitis in a setting with low prevalence of atopic disorders.

104. Flohr C, Nagel G, Weinmayr G, Kleiner A, Strachan DP, Williams HC, et al. Lack of evidence for a protective effect of prolonged breastfeeding on childhood eczema: lessons from the International Study of Asthma and Allergies in Childhood (ISAAC) Phase Two. Br J Dermatol. 2011;165:1280-9.

105. Funkhouser LJ, Bordenstein SR. Mom knows best: the universality of maternal microbial transmission. PLoS Biol. 2013;11:e1001631.

106. Pfefferle PI, Büchele G, Blümer N, et al. Cord blood cytokines are modulated by maternal farming activities and consumption of farm dairy products during pregnancy: the PASTURE Study. J Allergy Clin Immunol. 2010;125: 108-115.e3. 
107. Peroni DG, Piacentini GL, Bodini A, Pigozzi R, Boner AL. Transforming growth factor- $\beta_{1}$ is elevated in unpasteurized cow's milk. Pediatr Allergy Immunol. 2009;20:42-4.

108. Sausenthaler S, Koletzko S, Schaaf B, Lehmann I, Borte $\mathrm{M}$, Herbarth $\mathrm{O}$, et al. Maternal diet during pregnancy in relation to eczema and allergic sensitization in the offspring at $2 \mathrm{y}$ of age. Am J Clin Nutr. 2007;85:530-7.

109. Vuillermin PJ, Macia L, Nanan R, Tang MLK, Collier F, Brix S. The maternal microbiome during pregnancy and allergic disease in the offspring. Semin Immunopathol. 2017;39:669-75.

110. Cuello-Garcia CA, Brozek JL, Fiocchi A, et al. Probiotics for the prevention of allergy: a systematic review and meta-analysis of randomized controlled trials. J Allergy Clin Immunol. 2015;136:952-61.

111.• Makrgeorgou A, Leonardi-Bee J, Bath-Hextall FJ, et al. Probiotics for treating eczema. Cochrane Database Syst Rev. 2018;11:CD006135

This Cochrane systematic review found that currently available probiotics have no impact in improving AD symptoms or improving quality of life with patients with eczema.

112. West CE, Jenmalm MC, Kozyrskyj AL, Prescott SL. Probiotics for treatment and primary prevention of allergic diseases and asthma: looking back and moving forward. Expert Rev Clin Immunol. 2016;12:62539.

113. Shibata R, Kimura M, Takahashi H, Mikami K, Aiba Y, Takeda $\mathrm{H}$, et al. Clinical effects of kestose, a prebiotic oligosaccharide, on the treatment of atopic dermatitis in infants. Clin Exp Allergy. 2009;39:1397-403.

114. Boženský J, Hill M, Zelenka R, Skýba T. Prebiotics do not influence the severity of atopic dermatitis in infants: a randomised controlled trial. PLoS One. 2015;10:e0142897.

115. Cuello-Garcia C, Fiocchi A, Pawankar R, Yepes-Nuñez JJ, Morgano GP, Zhang Y, et al. Prebiotics for the prevention of allergies: a systematic review and metaanalysis of randomized controlled trials. Clin Exp Allergy. 2017;47:1468-77.

116. Suárez AL, Feramisco JD, Koo J, Steinhoff M. Psychoneuroimmunology of psychological stress and atopic dermatitis: Pathophysiologic and therapeutic updates. Acta Derm Venereol. 2012;92:7-15.

117. Hu C, Nijsten T, Pasmans SGMA, Jongste JC, Jansen PW, Duijts L. Associations of eczema phenotypes with emotional and behavioural problems from birth until school age. The Generation R Study. Br J Dermatol. 2020;183:311-20.

118. Pape K, Tamouza R, Leboyer M, Zipp F. Immunoneuropsychiatry - novel perspectives on brain disorders. Nat Rev Neurol. 2019;15:317-28.

119. Bergink V, Gibney SM, Drexhage HA. Autoimmunity, inflammation, and psychosis: a search for peripheral markers. Biol Psychiatry. 2014;75:324-31.

120. Stuart MJ, Singhal G, Baune BT. Systematic review of the neurobiological relevance of chemokines to psychiatric disorders. Front Cell Neurosci. 2015;9:1.
121. Arck PC, Slominski A, Theoharides TC, Peters EMJ, Paus R. Neuroimmunology of stress: skin takes center stage. J Invest Dermatol. 2006;126:1697-704.

122. Wilson SR, Thé L, Batia LM, Beattie K, Katibah GE, McClain SP, et al. XThe epithelial cell-derived atopic dermatitis cytokine TSLP activates neurons to induce itch. Cell. 2013;155:285-95.

123. Furue M, Yamamura K, Kido-Nakahara M, Nakahara T, Fukui Y. Emerging role of interleukin-31 and interleukin-31 receptor in pruritus in atopic dermatitis. Allergy Eur J Allergy Clin Immunol. 2018;73:2936.

124. Ruzicka T, Hanifin JM, Furue M, Pulka G, Mlynarczyk I, Wollenberg A, et al. Anti-Interleukin-31 Receptor A Antibody for Atopic Dermatitis. N Engl J Med. 2017;376:826-35.

125. Nocchi L, Roy N, D'Attilia M, Dhandapani R, Maffei M, Traista A, et al. Interleukin-31-mediated photoablation of pruritogenic epidermal neurons reduces itch-associated behaviours in mice. Nat Biomed Eng. 2019;3:114-25.

126. Yosipovitch G, Berger T, Fassett MS. Neuroimmune interactions in chronic itch of atopic dermatitis. J Eur Acad Dermatology Venereol. 2020;34:239-50

This review summarises the key neuroimmune pathways and proposes treatment targets for managing chronic itch in AD.

127. Sanders KM, Akiyama T. The vicious cycle of itch and anxiety. Neurosci Biobehav Rev. 2018;87:17-26.

128. Cui Y, Miao K, Niyaphorn S, Qu X. Production of gamma-aminobutyric acid from lactic acid bacteria: A systematic review. Int J Mol Sci. 2020;21. https://doi. org/10.3390/ijms21030995.

129. Sen CY, Chiang BL. Mechanism of sleep disturbance in children with atopic dermatitis and the role of the circadian rhythm and melatonin. Int J Mol Sci. 2016;17. https://doi.org/10.3390/ijms17040462.

130. Silverberg JI, Garg NK, Paller AS, Fishbein AB, Zee PC. Sleep disturbances in adults with eczema are associated with impaired overall health: A US populationbased study. J Invest Dermatol. 2015;135:56-66.

131. Irwin MR. Sleep and inflammation: partners in sickness and in health. Nat Rev Immunol. 2019;19:70215.

132.• Silverberg JI. Comorbidities and the impact of atopic dermatitis. Ann Allergy Asthma Immunol. 2019;123:144-51

This paper outlines the physical and psychosocial sequelae of $\mathrm{AD}$ on patients and highlights strategies for management of comorbidities in an effort to improve patient outcomes.

133. Solomon I, Ilie MA, Draghici C, Voiculescu VM, Căruntu C, Boda D, et al. The impact of lifestyle factors on evolution of atopic dermatitis: An alternative approach (review). Exp Ther Med. 2019;17:107884.

133.• Jiang C, Wang X, Li X, et al. Dynamic human environmental exposome revealed by longitudinal personal monitoring. Cell. 2018. https://doi.org/10. 1016/j.cell.2018.08.060

This study highlights a potential future approach for 
exposome based research. It outlines the measurement of individual biological and chemical geotemporal exposure niches, in an effort to characterise the exposure, its timing and its dose on an individual level.

135. Loh M, Sarigiannis D, Gotti A, Karakitsios S, Pronk A Kuijpers E, et al. How sensors might help define the external exposome. Int J Environ Res Public Health. 2017;14. https://doi.org/10.3390/ijerph14040434.

\section{Publisher's Note}

Springer Nature remains neutral with regard to jurisdictional claims in published maps and institutional affiliations. 